\title{
Synaptic Targeting of Retrogradely Transported Trophic Factors in Motoneurons: Comparison of Glial Cell Line- Derived Neurotrophic Factor, Brain-Derived Neurotrophic Factor, and Cardiotrophin-1 with Tetanus Toxin
}

\author{
Howard B. Rind, ${ }^{\star}$ Rafal Butowt, ${ }^{*}$ and Christopher S. von Bartheld \\ Department of Physiology and Cell Biology, University of Nevada School of Medicine, Reno, Nevada 89557
}

\begin{abstract}
Glial cell line-derived neurotrophic factor (GDNF), brain-derived neurotrophic factor (BDNF), and cardiotrophin-1 (CT-1) are the most potent neurotrophic factors for motoneurons, but their fate after retrograde axonal transport is not known. Internalized trophic factors may be degraded, or they may be recycled and transferred to other neurons, similar to the known route of tetanus toxin. We tested whether neonatal rat hypoglossal motoneurons target retrogradely transported trophic factors to synaptic sites on their dendrites within the brainstem and subsequently transfer these trophins across the synaptic cleft to afferent synapses (transsynaptic transcytosis). Motoneurons retrogradely transport from the tongue radiolabeled GDNF, BDNF, and CT-1 as well as tetanus toxin. Quantitative autoradiographic electron microscopy showed that GDNF and BDNF were transported into motoneuron dendrites with labeling densities similar to those of tetanus toxin. Although tetanus toxin accumulated rapidly (within $8 \mathrm{~h}$ ) at presynaptic sites, GDNF accumulated at synapses more slowly (within $15 \mathrm{~h}$ ), and CT-1 never associated with synapses. Thus, some retrogradely transported neurotrophic factors are trafficked similarly but not identically to tetanus toxin. Both GDNF and BDNF accumulate at the external (limiting) membrane of multivesicular bodies within proximal dendrites. We conclude that tetanus toxin, GDNF, and BDNF are released from postsynaptic sites and are internalized by afferent presynaptic terminals, thus demonstrating transsynaptic transcytosis. CT-1, however, follows a strict degradation pathway after retrograde transport to the soma. Synaptic and transcytotic trafficking thus are restricted to particular neurotrophic factors such as GDNF and BDNF.
\end{abstract}

Key words: electron microscopy; hypoglossal motoneuron; axonal transport; multivesicular body; synapse; transcytosis

\section{Introduction}

Neurons internalize macromolecules at nerve terminals and move them by retrograde axonal transport to their cell bodies (Dumas et al., 1979). Not all of these macromolecules are degraded in the cell body, but some can be recycled and transcytosed to afferent synapses, as shown by the efficient targeting of tetanus toxin to afferent synapses after retrograde axonal transport. This mechanism of transsynaptic transcytosis is particularly prominent in motoneurons (Schwab and Thoenen, 1977a; Schwab et al., 1979). It is likely that neurons developed efficient transcytotic transport pathways for the purpose of trafficking trophic substances across multiple synapses (Schwab and

\footnotetext{
Received Feb. 25, 2004; revised Nov. 24, 2004; accepted Nov. 27, 2004.

This work was supported by National Institutes of Health Grants NS 35931 and EY 12841 (C.S.v.B.), TW 05700 (C.S.v.B. and R.B.), and NS 47216 (R.B.). We thank Clifford Stratton and XiaoXia Wang for assistance with electron microscopy and insightful discussions on the biology of neurotrophic factor sorting. William Hatton kindly assisted with digital artwork. The trophic factor BDNF was kindly provided by Regeneron (Tarrytown, NY), and GDF-15 was provided by Klaus Unsicker (University of Heidelberg, Heidelberg, Germany).

${ }^{*} H . B . R$. and R.B. contributed equally to this work.

Correspondence should be addressed to Christopher von Bartheld, Department of Physiology and Cell Biology, Mailstop 352, University of Nevada School of Medicine, Reno, NV 89557. E-mail: chrisvb@physio.unr.edu.

H. B. Rind's present address: AmCyte Inc., 2825 Santa Monica Boulevard, Suite 200, Santa Monica, CA 90404. D01:10.1523/JNEUROSCI.4322-04.2005

Copyright $\odot 2005$ Society for Neuroscience $\quad$ 0270-6474/05/250539-11\$15.00/0
}

Thoenen, 1977b; Butowt and von Bartheld, 2003; von Bartheld, 2004). However, to date, no trophic factor has been identified with synaptic targeting properties and transcytotic efficiencies that resemble those of tetanus toxin.

Numerous trophic factors are expressed in peripheral targets of motoneurons, including neurotrophins, glial cell line-derived neurotrophic factor (GDNF), cardiotrophin-1 (CT-1), and fibroblast growth factors (Oppenheim, 1996; Arce et al., 1998). These trophic factors can be retrogradely transported by motoneurons from the periphery to their cell bodies (Grothe and Unsicker, 1992; Yan et al., 1993; Leitner et al., 1999; Rind and von Bartheld, 2002b; Chen et al., 2003). Brain-derived neurotrophic factor (BDNF) and GDNF can be transcytosed by neurons and thus are not necessarily degraded after internalization and retrograde axonal transport (von Bartheld et al., 2001; von Bartheld, 2004). However, the fate of internalized neurotrophic factors after retrograde axonal transport, to date, has not been examined in motoneurons, despite an intense interest in functions of motoneuronotrophic molecules and potential clinical implications for treatment of degenerative and traumatic motoneuron disorders (Sendtner, 1996).

Here, we report on the fate of retrogradely transported trophic factors by using quantitative electronmicroscopic autoradiogra- 
phy in neonatal rat hypoglossal motoneurons. This model system was chosen because hypoglossal motoneurons lack direct monosynaptic afferent proprioceptive input from the tongue (Neuhuber and Zenker, 1989; Fay and Norgren, 1997; Zhang et al., 2001), thus providing a "clean" retrograde transport model system devoid of any potential contamination of afferent synapses on motoneurons by anterograde (sensory) axonal transport. We compared the accumulation and transsynaptic transfer of BDNF, GDNF, CT-1, and tetanus toxin in the hypoglossal nucleus. We report that two of the tested trophic factors, GDNF and BDNF, are transported efficiently not only to hypoglossal cell bodies but also to their dendrites where they accumulate in multivesicular bodies (MVBs) at postsynaptic sites of afferent synapses and can also be transferred across afferent synapses (transsynaptic transcytosis). Tetanus toxin accumulated rapidly in afferent synapses presynaptically, whereas GDNF accumulated at synapses more slowly, and CT-1 was not targeted to synapses. These data show that significant fractions of internalized GDNF and BDNF escape degradation and are recycled by motoneurons for additional functions, possibly synaptic plasticity. A trafficking pathway similar to that used by tetanus toxin thus may be used by endogenous neurotrophic factors that are produced in muscles (Oppenheim, 1996) and are trafficked retrogradely by motoneurons (Leitner et al., 1999; Russell et al., 2000; Chen et al., 2003). Preliminary data of this work have been presented previously (Rind and von Bartheld, 2002c; Rind et al., 2004).

\section{Materials and Methods}

Materials. Neonatal Wistar rats were obtained from untimed pregnant females (Simonsen Labs, Gilroy, CA). The animal studies were conducted in accordance with the Policies on the Use of Animals and Humans in Neuroscience Research (1995), and animal protocols were approved by the local animal care committee. A total of 47 rat pups were used. ${ }^{125} \mathrm{I}-\mathrm{Na}$ was from PerkinElmer Life Sciences (Boston, MA). GDNF and CT-1 were purchased from Peprotech (Rocky Hill, NJ), tetanus toxin C-fragment (TTC) was from Calbiochem (La Jolla, CA), BDNF was a kind gift from Regeneron (Tarrytown, NY), and growth/differentiation factor-15 (GDF-15) was kindly provided by Jens Strelau and Klaus Unsicker (University of Heidelberg, Heidelberg, Germany). All electron microscopy (EM) tissue processing reagents were from EM Sciences (Gibbstown, NJ) except for lead citrate (Sigma, St. Louis, MO). DiI was from Molecular Probes (Eugene, OR). Autoradiographic developer (D19) and fixative (rapid fix) were from Kodak (Rochester, NY).

Protein iodination and methods for in vivo injections. Proteins were radio-iodinated to specific activities of $92-141 \mathrm{cpm} / \mathrm{pg}$ BDNF, 90-94 $\mathrm{cpm} / \mathrm{pg}$ GDNF, 25-62 cpm/pg CT-1, 98-143 cpm/pg basic fibroblast growth factor (bFGF), 35-73 cpm/pg tetanus toxin C-fragment, and 27$117 \mathrm{cpm} / \mathrm{pg}$ GDF-15 by using lactoperoxidase as described previously (von Bartheld, 2001). Four- to 5-d-old neonatal rats were anesthetized by hypothermia just before tongue injections. For autoradiographic EM studies, $2 \mu \mathrm{l}$ of a $2 \%$ DiI solution (in 100\% ethanol) was injected into the left side of each rat tongue. Several minutes later, 10-200 ng of the radio-iodinated protein was injected into the right side of each DiIinjected tongue. Although one side of the rat tongue was targeted, often the injected peptides diffused to both sides of the tongue and labeled hypoglossal neurons on both sides in the medulla. After injections, rat pups were placed under heat lamps. For autoradiographic light microscopy studies, the same injection methods were used except that DiI was not administered.

Tissue processing for light microscopic analyses. Fifteen hours after tongue injections, animals were injected with an overdose of Nembutal. Rat pups were perfused transcardially with 10 volumes of $4 \%$ paraformaldehyde (PFA) in PBS, pH 7.4. Isolated brains were postfixed, dehydrated, and embedded in paraffin as described previously (Rind and von Bartheld, 2002a). Transverse sections of $14 \mu \mathrm{m}$ thickness were cut on a rotary microtome, mounted on gelatin-coated slides, dried overnight at $43^{\circ} \mathrm{C}$, deparaffinized in xylene, briefly immersed in $100 \%$ ethanol, and air dried. The distribution of retrogradely transported proteins was analyzed by visualizing emulsion-coated, exposed, and developed brain sections under dark- and bright-field optics on an upright Nikon (Tokyo, Japan) Eclipse E600 microscope. Analog dark-field micrographs were photographed with Kodak Techpan film, printed, and digitized with Adobe Photoshop (Adobe Systems, San Jose, CA).

Tissue processing for electron microscopic analyses. Eight or $15 \mathrm{~h}$ after tongue injections, rat pups were perfused transcardially with 10 volumes of $2 \%$ PFA in $0.1 \mathrm{M}$ cacodylate buffer, $\mathrm{pH} 7.4$, containing $1.5 \%$ EM grade glutaraldehyde. Tongues were dissected and gamma-counted to verify successful injections. Brains were removed, and the total amount of radioactivity in each brain was quantified in a gamma-counter. Brains containing at least $400 \mathrm{cpm}$ of radioactivity were then sliced with a razor blade (through the brainstem) in the transverse plane at $\sim 1 \mathrm{~mm}$ thickness. Each slice was placed in a fresh drop of fixative and analyzed for the presence of retrogradely transported DiI under an inverted fluorescent Nikon Eclipse TE200 microscope. DiI label within the brainstem was compared with the known anatomical distribution of the rat hypoglossal motor nucleus (Paxinos and Watson, 1998). Under fluorescence optics, a $4 \mathrm{~mm}^{3}$ piece of hypoglossal nucleus was microdissected away from the remainder of the brain slice using a number 14 scalpel blade, and the tissue was placed in fresh fixative. Total radioactivity within each microdissected hypoglossal nucleus was quantified after $90 \mathrm{~min}$ postfixation. Hypoglossal tissue was washed, postfixed in osmium tetroxide, dehydrated, infiltrated, and embedded in Spurr's resin (von Bartheld, 2001) and gamma-counted. Typically, $100-700 \mathrm{cpm}$ remained in tissue samples after embedding. One-micrometer-thick (semithin) sections were cut through each EM block, mounted on glass slides, and stained with Toluidine blue to verify the presence of hypoglossal motoneurons. Once hypoglossal motoneurons were identified on the surface of the block face, $\sim 95 \mathrm{~nm}$ thin sections were cut through the hypoglossal nucleus using a Leica (Nussloch, Germany) ultramicrotome and collected on uncoated copper mesh grids.

Autoradiography. For autoradiographic electron microscopy, EM grids with thin sections were placed on glass slides and coated with a monolayer of Ilford (Basildon, UK) L4 emulsion diluted to $40 \%$ in deionized water (Caro and van Tubergen, 1962). After brief air drying, grid-containing slides were packaged in dessicated slide boxes and stored in the dark at $4^{\circ} \mathrm{C}$ for $1.5-10$ months before developing, fixing, and staining with lead citrate (von Bartheld, 2001). For autoradiographic light microscopy, deparaffinized brain sections were coated with Kodak NTB-2 emulsion and exposed dessicated in the dark at $4^{\circ} \mathrm{C}$ for $4-8$ weeks. After exposure, slides were developed, fixed, and lightly counterstained with thionin.

Excess cold competition studies. To determine whether the transport of radiolabeled trophic factors to the hypoglossal motor nucleus was receptor mediated, three to four animals were coinjected with 50- to 100-fold excess cold GDNF, BDNF, or CT-1 in the tongue. The brains were processed for light-microscopic autoradiography as described above. Developed and lightly counterstained sections were analyzed in dark-field illumination, and representative sections of the hypoglossal nucleus were photographed with Techpan film.

Analysis of EM autoradiographs. The ultrastructural distribution of retrogradely transported factors was quantified in both the cell bodies and proximal dendrites of hypoglossal motoneurons. Developed grids were stained with lead citrate and viewed on a Philips (FEI, Hillsboro, OR) CM-10 transmission electron microscope. Autoradiographic grains were randomly photographed within the hypoglossal nucleus at $6600 \times$ magnification using Kodak electron microscope film and printed at a final magnification of $\sim 17,000 \times$. For the $15 \mathrm{~h}$ time point, a total of 182 prints were analyzed for GDNF grains, 205 prints for BDNF grains, 157 prints for CT-1 grains, and 102 prints for tetanus toxin grains. For the $8 \mathrm{~h}$ time point, a total of 92 prints were analyzed for GDNF grains, 79 for CT-1 grains, and 101 prints for tetanus toxin grains. The labeling densities of organelles within hypoglossal motoneuron cell bodies and proximal dendrites were quantified by applying the circle probability method with a half distance of $90 \mathrm{~nm}$ (Salpeter et al., 1978) to printed photomicrographs as detailed below. Hypoglossal motoneurons were distin- 
guished from other cell types (e.g., glia and interneurons) in electron micrographs using established criteria (Takasu and Hashimoto, 1988; Peters et al., 1991; Nunez-Abades et al., 1994). Hypoglossal motoneuron proximal dendrites were distinguished from distal dendrites by the presence of ribosomes in the former and their absence in the latter. The labeling density of each class of organelle was quantified from photomicrographs by dividing the percentage of autoradiographic grains overlying such organelles by the percentage fractional area occupied by that class of organelle. For example, if $20 \%$ of the grains were found to overlay hypoglossal mitochondria and if the fractional area that all hypoglossal mitochondria occupied represented $20 \%$ (of the total area of hypoglossal motoneurons), then the labeling density would be $20 \%$ divided by $20 \%$, which equals 1.0. Labeling densities $\leq 1.0$ were considered to represent randomly distributed grains, whereas labeling densities $>1.0$ indicate a specific association of silver grains with that type of organelle. To identify the organelle(s) responsible for each autoradiographic grain, a circle with a $90 \mathrm{~nm}$ radius was centered over each grain. All organelles falling within this circle were tallied and considered to contain the radioactive factor responsible for the silver grain (Salpeter et al., 1978). To calculate the fractional area for each hypoglossal organelle type, a transparent grid was laid over the photomicrographs, and the frequency of organelles intersecting the grid was scored for each treatment group. This method is well established for determining the labeling densities of organelles in autoradiographic electron micrographs (Fertuck and Salpeter, 1974; Salpeter et al., 1978; Butowt and von Bartheld, 2001; von Bartheld, 2001). The significance of differences between labeling densities was tested for the data obtained with 279 GDNF silver grains by dividing them into groups and performing paired $t$ test analyses. For example, a labeling density of 1.9 for "terminals" was significantly different $(p<0.05)$ from a labeling density of 1.2 for "plasma membrane."

For the $15 \mathrm{~h}$ time point, the total number of silver grains analyzed in hypoglossal motoneuron cell bodies and proximal dendrites was 210 and 279 ( $\left.{ }^{125} \mathrm{I}-\mathrm{GDNF}\right), 234$ and 110 ( $\left.{ }^{125} \mathrm{I}-\mathrm{BDNF}\right), 152$ and 161 ( $\left.{ }^{125} \mathrm{I}-\mathrm{CT}-1\right)$, and 177 and 157 ( ${ }^{125}$ I-tetanus toxin C-fragment), respectively. For the $8 \mathrm{~h}$ time point, the total number of silver grains analyzed in hypoglossal motoneuron cell bodies and proximal dendrites was 106 and $60\left({ }^{125} \mathrm{I}-\right.$ GDNF), 159 and $65\left({ }^{125} \mathrm{I}\right.$-CT-1), and 71 and $62\left({ }^{125} \mathrm{I}\right.$-tetanus toxin C-fragment), respectively; BDNF was not examined because of too low radioactivity at $8 \mathrm{~h}$. Only identified motor neurons and proximal dendrites that matched the inclusion criteria were scored, meaning that many silver grains on photomicrographs (e.g., those over axons, distal dendrites, or glia) were excluded from the analysis. Each treatment group was analyzed by at least two of the investigators independently. Sections from two to four different animals and samples were analyzed for each treatment group. The number of labeled and unlabeled multivesicular bodies in proximal dendrites and their association with postsynaptic densities (within $400 \mathrm{~nm}$ distance from a synaptic density) was scored separately and compared for the different treatment groups; the theoretical chances of association were calculated based on fractional area measurements.

To localize the source of radioactivity and its distance from the external (limiting) membrane of MVBs, the technique of LaVail et al. (1983) was used as described previously for the plasma membrane. In brief, the distance between the center of each silver grain and the external membrane of MVBs was measured for each silver grain that was associated with (within $300 \mathrm{~nm}$ from) MVBs for GDNF and BDNF grains. The data were plotted in frequency histograms as a function of the distance from the external MVB membrane; MVBs within dendrites and MVBs within cell bodies were scored and plotted separately. Statistically significant differences between groups were assessed with the Wilcoxon signed rank-sum test.

Precipitation of transported radiolabeled proteins. To determine whether radiolabeled trophic factors or tetanus toxin fragment $\mathrm{C}$ remained intact after their retrograde transport to hypoglossal motoneurons, ${ }^{125} \mathrm{I}-\mathrm{GDNF},{ }^{125} \mathrm{I}$-BDNF, ${ }^{125} \mathrm{I}-\mathrm{CT}-1$, or ${ }^{125} \mathrm{I}$-tetanus toxin C fragment were injected together with DiI into the tongues of three to five anesthetized rat pups as described above. Fifteen hours after injection, rats were decapitated, and brainstem slices were cut and analyzed under a fluorescent microscope. DiI-containing hypoglossal nuclei were ex- cised from serial sections and pooled in cold lysis buffer (2\% SDS, 100 mм DTT, 60 mм Tris, pH 6.8). Hypoglossal tissue was then repeatedly passed through a 20 gauge needle to facilitate tissue solubilization. Trichloroacetic acid (TCA) was added to each sample to a final concentration of $20 \%$, incubated on ice for $20 \mathrm{~min}$, and centrifuged in a Microfuge at $14,000 \mathrm{rpm}$ at $4^{\circ} \mathrm{C}$. Supernatants and precipitates were gammacounted separately to quantify the fractions of radioactivity within proteins and those constituting free iodine or small degradation products (Johnson et al., 1978).

\section{Results}

\section{Retrograde transport of GDNF, BDNF, and CT-1 at the} light-microscopic level

We examined the trophic factors GDNF, BDNF, CT-1, and bFGF, because these factors have been reported to functionally affect rodent hypoglossal motoneurons (Grothe and Unsicker, 1992; Chiu et al., 1994; Oppenheim et al., 2000, 2001; Blesch and Tuszynski, 2001). Tetanus toxin and bFGF are retrogradely transported by rat hypoglossal motoneurons (Fishman and Carrigan, 1987; Grothe and Unsicker, 1992; Miana-Mena et al., 2003), but such transport has not been examined for other exogenous trophic factors in this system. We first tested whether GDNF, BDNF, and CT-1 were transported retrogradely in rat pup hypoglossal motoneurons. As expected, GDNF, BDNF, and CT-1 were transported retrogradely to the hypoglossal nucleus $15 \mathrm{~h}$ after injection into the tongue, either bilaterally (Fig. $1 A-C$ ) or ipsilaterally (Fig. 2A). The retrograde axonal transport of each of these trophic factors was competed by excess cold factor (and thus likely was receptor mediated) (Johnson et al., 1978). Excess ( $\sim 50$ - to 100 -fold) cold trophic factor, coinjected with the radiolabeled factor in the tongue, significantly diminished radioactivity in the brainstem by both gamma-counting as well as autoradiography (Fig. $2 B-G$ ), indicating that internalization and axonal transport of these factors is receptor mediated in developing motoneurons, similar to previous reports on adult motoneurons for bFGF (Grothe and Unsicker, 1992) and neurotrophins (DiStefano et al., 1992). The specificity of internalization and/or retrograde axonal transport was further attested by the complete lack of transport to the hypoglossal motor nucleus of another trophic factor, GDF-15 (data not shown), a protein that is known to be trophic in other parts of the motor system (Strelau et al., 2003).

Regarding the accumulation of trophic factors in the hypoglossal nucleus, two striking differences were observed between these factors at the light-microscopic level. First, significantly more ${ }^{125} \mathrm{I}$-GDNF accumulated in the hypoglossal nucleus compared with ${ }^{125} \mathrm{I}-\mathrm{BDNF},{ }^{125} \mathrm{I}-\mathrm{bFGF}$, or ${ }^{125} \mathrm{I}-\mathrm{CT}-1$, and ${ }^{125} \mathrm{I}-$ GDF-15 was not transported at all. This difference was consistent for all animals injected with these factors and was similarly reflected in the gamma counts obtained from dissected hypoglossal nuclei for ultrastructural analysis (see below). These differences were not attributable to differences in injections, because similar levels of trophic factor were retained in the injected tongue at the time of killing. Typical ranges in the dissected tongue include the following: GDNF, 20-60 ng; BDNF, 20-70 ng; bFGF, 50-200 ng; CT-1, 10-25 ng; tetanus toxin, 30-130 ng; GDF-15, 20-30 ng. GDNF accumulation in dissected hypoglossal nuclei (607 \pm 70.8 cpm, SEM; $n=7)$ was comparable with tetanus toxin (1058 \pm $402.9 \mathrm{cpm} ; n=3)$ but consistently higher than CT-1 (132 \pm 15.4 cpm; $n=8)$; CT-1 was higher than $\operatorname{BDNF}(55 \pm 7.0 \mathrm{cpm} ; n=6)$, and BDNF was marginally higher than bFGF ( $47 \pm 5.5 \mathrm{cpm} ; n=$ $6)$. Because the gamma counts in dissected hypoglossal nuclei were particularly low for bFGF, we focused the ultrastructural analysis on the three more robustly transported trophic factors, GDNF, CT-1, and BDNF. 
The second difference between retrogradely transported GDNF, BDNF, and CT-1 was observed in the pattern of transport. In the case of CT-1, silver grain accumulation was restricted to the hypoglossal motor cell bodies (Fig. 1C,E) (also revealed by thionin counterstaining) (data not shown), but the label extended beyond the hypoglossal nucleus proper and included neuropil for GDNF (Fig. $1 A, F$ ), tetanus toxin (Fig. $1 D$ ), and, to some extent, BDNF (Fig. $1 B$ ). In the case of GDNF, the pattern of grain distribution was marked by linear arrays of grain accumulation (Fig. $1 F$ ) that closely reflect the known distribution of hypoglossal motoneuron dendrites (Wan et al., 1982). These data indicate that after the retrograde transport of GDNF to hypoglossal cell bodies, a significant fraction of GDNF may be sorted to hypoglossal dendrites, similar to the known movement of tetanus toxin (Fishman and Carrigan, 1987). Because neuronal dendrites cannot be discerned unambiguously in paraffin sections at the light microscopic level, we examined at the ultrastructural level whether GDNF and other trophic factors as well as tetanus toxin were transported into hypoglossal motoneuron dendrites after arrival in the cell body.

\section{Ultrastructural analysis of the}

distribution of retrogradely transported proteins in the hypoglossal motoneuron soma at $15 \mathrm{~h}$

Many retrogradely transported trophic factors such as nerve growth factor (NGF) are destined for degradation by lysosomes, and the proteolytic fragments or free iodine are rapidly expelled (Johnson et al., 1978; Claude et al., 1982a), but internalized macromolecules can also be recycled and targeted for transcytosis to synaptic sites (Schwab and Thoenen, 1977a; Schwab et al., 1979; Butowt and von Bartheld, 2001; von Bartheld, 2004). To identify the intracellular pathways and organelles that associate with internalized trophic factors, quantitative autoradiography was used at the electronmicroscopic level. Hypoglossal motoneuron cell bodies can be easily identified ultrastructurally because of their large size and abundant rough endoplasmic reticulum (Takasu and Hashimoto, 1988). With exposure times of 2-10 months, silver grains were readily observed over motoneuron cell bodies (Fig. 3A-F). In our "cell body" analysis, we classified the organelles as listed in Table 1. Among the endosomes, we attempted to distinguish between lysosomes, dense endosomes, and light endosomes based on their densities (examples are shown in Fig. $3 A-C)$. For the category "Golgi," we included those vesicles that were closely associated with (immediately adjacent to) the Golgi apparatus (Fig. $3 F$ ). The fractional area of organelles was measured for all treatment groups separately, and because the values were very similar, the ranges are listed (Table 1), and the averages were used to calculate the labeling densities of organelles.

Consistent with a previous report on tetanus toxin localization in adult rat spinal cord motoneurons (Schwab and Thoenen, 1976, 1977a), tetanus toxin C fragment accumulated in dense endosomes (Table 1). Curiously, tetanus toxin $\mathrm{C}$ fragment accumulated much less in MVBs in the soma than the trophic factors (Table 1) or tetanus toxin in adult spinal cord motoneurons (Schwab and Thoenen, 1976, 1977a). Although CT-1 clearly enters a degradation pathway in hypoglossal motor neurons, as evidenced by the high labeling densities for dense endosomes and lysosomes, GDNF and tetanus toxin did not accumulate in lysosomes, and these proteins were much less frequent in dense endosomes than CT-1. The labeling densities in the Golgi apparatus and at the plasma membrane were approximately comparable between the four proteins, with the exception of CT- 1 that was not targeted to the plasma membrane (Table 1). These data indicate that CT-1, similar to NGF in other systems (Schwab and Thoenen, 1976; Claude et al., 1982a,b), is targeted to a rapid degradation pathway in hypoglossal motoneurons, whereas tetanus toxin, GDNF, and, to a lesser extent, BDNF avoid degradation, possibly to allow for increased trafficking into hypoglossal dendrites and beyond (see below).

\section{Ultrastructural analysis of the distribution of retrograde proteins in hypoglossal proximal dendrites and afferent synapses at $15 \mathrm{~h}$}

We restricted our analysis of dendritic distribution of transported proteins to the proximal dendrites of hypoglossal motoneurons and the afferent synapses contacting those proximal dendrites. The reason for this is that distal dendrites and unmyelinated axons can be difficult to distinguish in the developing 

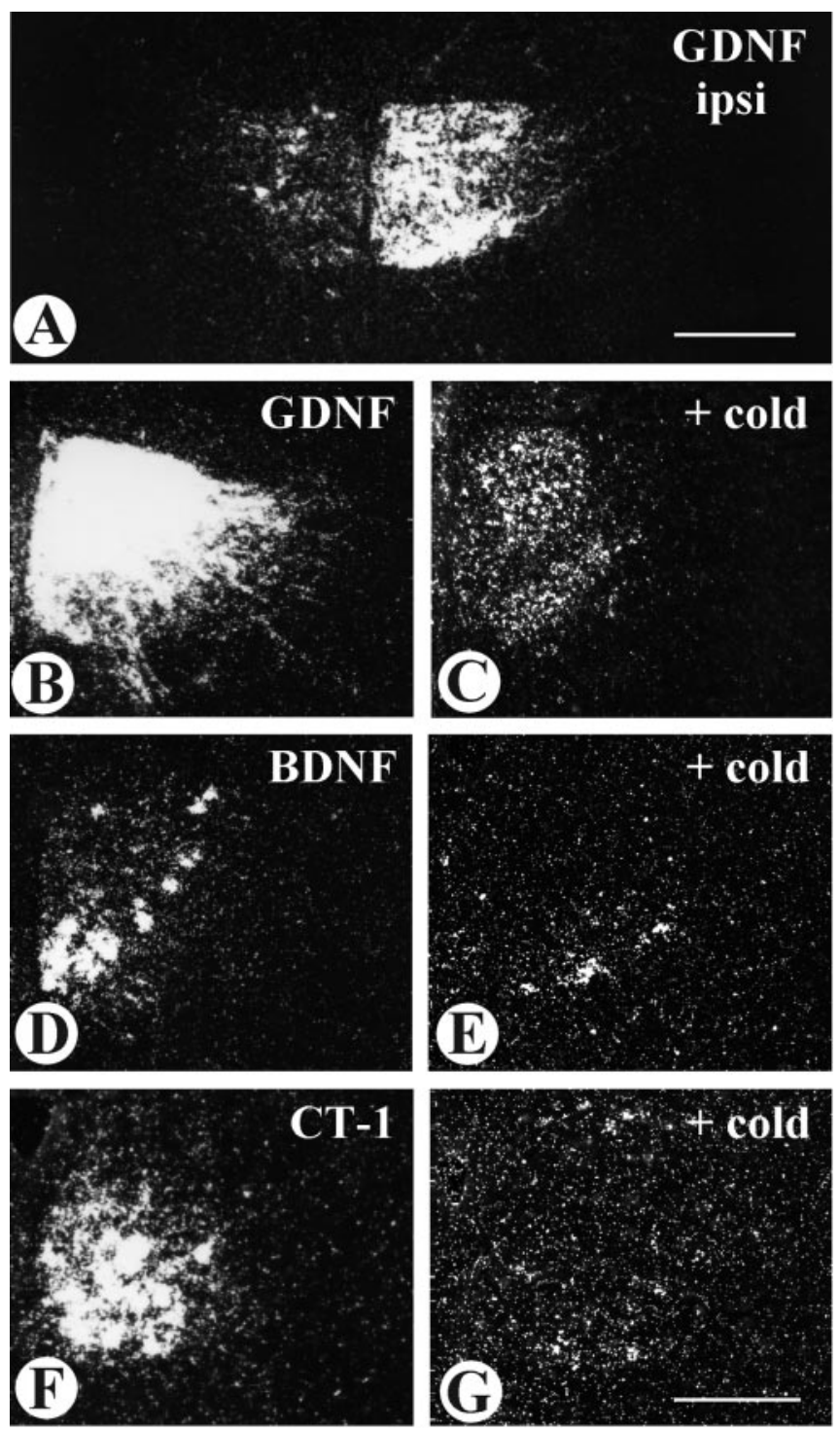

Figure 2. A-G, Specificity and involvement of receptors in transport of radiolabeled proteins from the tongue to the hypoglossal nucleus in neonatal rats as seen in representative sections viewed in dark-field illumination. In all cases between 10 and $20 \mathrm{ng}$, radiolabeled trophic factor was injected. $A$, Transport of radiolabeled GDNF predominantly to the ipsilateral hypoglossal nucleus (ipsi) when the injection is carefully restricted to one side of the tongue. Scale bar, 500 $\mu \mathrm{m} . B$, Transport of radiolabeled GDNF only. C, Transport of radiolabeled GDNF with 50- to 100 -fold excess cold GDNF. D, Transport of radiolabeled BDNF only. E, Transport of radiolabeled BDNF with 50- to 100-fold excess cold BDNF. F, Transport of radiolabeled CT-1 only. G, Transport of radiolabeled (T-1 with 50- to 100-fold excess cold (T-1. Scale bar: (in G) B-G, $200 \mu \mathrm{m}$.

brain (Vaughn, 1989). Proximal dendrites were defined as clearly having ribosomes present within the continuity of the structure and usually one or more afferent synapses impinging on them (Fig. $4 D$ ). The presence of Golgi or the nucleus was taken as markers of the cell body, and those structures were excluded from the dendritic analysis.

At $15 \mathrm{~h}$, tetanus toxin distributed prominently in dendrites, with some of the grains associated with MVBs and dense endosomes as well as afferent synapses (Table 2), as expected from previous work (Schwab and Thoenen, 1976, 1977a). The labeling density for tetanus toxin in terminals (2.8) was significantly higher than 1.0, as reported previously (Price et al., 1977; Schwab and Thoenen, 1977a). Among the trophic factors, GDNF and BDNF accumulated significantly in MVBs and similarly in dense endosomes as well as afferent synapses (Fig. 4A-F). Major fractions, $21-35 \%$, of all GDNF and BDNF within the proximal dendrites were associated with synapses, whereas the fractional area of this category averaged only $12-13 \%$ in the GDNF and BDNF cases. There was no specific label (labeling density, $\sim 1.0$ ) at the nonsynaptic plasma membrane, whereas the labeling densities at synapses were significantly higher (Table 2). CT-1, in contrast, showed a strikingly different pattern. Although CT-1 also accumulated in MVBs and dense endosomes of proximal dendrites (Table 2), it was conspicuously absent from the afferent synapses. None of the synaptic regions analyzed had labeling densities above 1.0, clearly showing that CT-1 is not targeted to a transsynaptic pathway, unlike the other two trophic factors, GDNF and BDNF. These data demonstrate that hypoglossal motoneurons distinguish between trophic factors that are trafficked into dendrites and afferent synapses and those that are apparently degraded after retrograde axonal transport.

\section{Ultrastructural analysis of the distribution of retrograde proteins at $8 \mathrm{~h}$}

Because the $15 \mathrm{~h}$ time point generates a "snapshot" of the distribution at only one time point, we also examined an earlier time point, $8 \mathrm{~h}$, to begin to assess the kinetics of retrograde trafficking. Although the labeling density profiles at the $8 \mathrm{~h}$ time point were, in many cases, similar to those at $15 \mathrm{~h}$, there were some notable differences (Tables 1,2). The earliest, heavily labeled organelle in the cell body appears to be the dense endosome. The endoplasmic reticulum (and possibly the Golgi apparatus) is involved at early time points for tetanus toxin $\mathrm{C}$ fragment $(8 \mathrm{~h})$, consistent with a recent nonquantitative report by Miana-Mena et al. (2003), but not at $15 \mathrm{~h}$ (Table 1 ). Tetanus toxin appears surprisingly rapidly in presynaptic terminals, whereas CT-1 appears surprisingly rapidly in lysosomes (Table 1). In the cell body, labeling densities for MVBs are high for GDNF and CT-1 at $8 \mathrm{~h}$, but they are conspicuously low for tetanus toxin. GDNF already accumulates in dendrites at postsynaptic sites at $8 \mathrm{~h}$ but has not yet crossed the synaptic cleft at this time point, as evidenced by labeling densities (LDs) $<1.0$ for presynaptic areas and terminals (Table 2). Although tetanus toxin, GDNF, and BDNF all eventually accumulate at synapses, tetanus toxin $\mathrm{C}$ fragment clearly uses a different pathway (not involving MVBs) to transfer to the dendrites, unlike GDNF and BDNF.

\section{Distribution of retrograde proteins at synapses}

A closer analysis and comparison of the distribution of tetanus toxin and the trophic factors GDNF and BDNF among afferent synapses showed that tetanus toxin accumulates rapidly (within $8 \mathrm{~h}$ ) on the presynaptic side of afferent synapses, whereas GDNF accumulated more slowly and on the postsynaptic side of the synaptic cleft (Fig. 5A,B; Table 2). Both GDNF and BDNF also cross the synaptic cleft at $15 \mathrm{~h}$, because they were found in terminals and at presynaptic membranes with increased LDs (Table 2). GDNF and BDNF were occasionally found in terminals (Fig. $4 F$ ), as seen more often with tetanus toxin (Schwab and Thoenen, 1977a). For the analysis of synaptic labeling (Fig. 5A,B), we distinguished between the (nonsynaptic) plasma membrane, postsynaptic membranes, presynaptic membranes, and the terminal region as shown in Figure $5 A$. These data indicate that the main site of accumulation for tetanus toxin is located on the presynaptic side, consistent with previous reports (Schwab and Thoenen, 1976, 1977a), whereas for GDNF and BDNF, it appears to be on the postsynaptic side and, most abundant, in MVBs (Figs. $4 B, C, 5 B$ ). This concept is consistent with the idea of a 
predominantly retrograde flux of trophic factors at motor synapses (Wang and Poo, 1997; Haubensak et al., 1998; Lessmann et al., 2003).

\section{Association of MVBs with postsynaptic sites}

During our analysis of GDNF and BDNF localization in proximal dendrites, we noticed that silver grains accumulated with unexpectedly high frequency in MVBs that were located in immediate vicinity of afferent synapses (Fig. 4A-C). When we quantified this, we found that $40-65 \%$ of all MVBs labeled with BDNF or GDNF were within $400 \mathrm{~nm}$ of postsynaptic densities (Fig. 6B). When we measured the relative frequency (fractional area) of MVBs in proximal dendrites and the relative frequency (fractional area) of afferent synapses, we found that GDNF-labeled MVBs were associated three times more frequently with postsynaptic sites than would be expected by chance. To determine whether this association of MVBs with synaptic densities (to our knowledge, not reported previously in the literature) may be induced by loading MVBs with particular retrograde trophic factors such as GDNF or BDNF, the hypoglossal nuclei loaded with retrograde GDNF or BDNF were compared with those treated with CT- 1 or tetanus toxin. CT-1- or tetanus toxin-treated neurons had no labeled MVBs associated with synapses (Fig. 6B), and unlabeled MVBs were very rare within $400 \mathrm{~nm}$ of postsynaptic densities, although the fractional area of MVBs in CT-1- or tetanus toxin-containing proximal dendrites was in the same range as those for GDNF or BDNF-containing neurons (data not shown). Thus, GDNF and BDNF do not seem to simply induce or increase MVB size or number but rather appear to direct MVBs to or prolong their association time with synapses. We found that hypoglossal neurons containing retrograde GDNF or BDNF had much larger numbers of labeled MVB profiles associated with postsynaptic densities than those neurons containing CT-1 or tetanus toxin (Fig. 6B). Furthermore, there were no corresponding trends in the labeling densities of MVBs within the cell bodies for the different trophic factor treatment groups (Fig. 6A, Table 1). These data indicate that MVBs are targeted specifically to afferent synapses when they are loaded with GDNF or BDNF and then have a particular affinity to the postsynaptic region in hypoglossal motoneurons but not when MVBs in the cell body are loaded with tetanus toxin or CT-1.

\section{Retrogradely transported proteins vary in their degradation fractions and correlate with lysosomal LDs}

Is there evidence that the retrogradely transported trophic factors (and tetanus toxin) revealed by autoradiography are intact proteins rather than small degradation products or free iodine? Our TCA precipitation analysis of retrogradely transported radiolabeled proteins showed considerable differences between proteins in their degraded and intact fractions. Approximately $75 \%$ of the total radioactive counts for ${ }^{125} \mathrm{I}-\mathrm{GDNF}$ within the hypoglossal nuclei were TCA precipitable and $\sim 60 \%$ for ${ }^{125}$ I-TTC, but only $40 \%$ for ${ }^{125} \mathrm{I}-\mathrm{BDNF}$ and only $28 \%$ for ${ }^{125} \mathrm{I}-\mathrm{CT}-1$ (Fig. $6 \mathrm{D}$ ). This indicates that after the retrograde transport of GDNF and tetanus toxin, the large majority of radioactivity observed in the hypo-
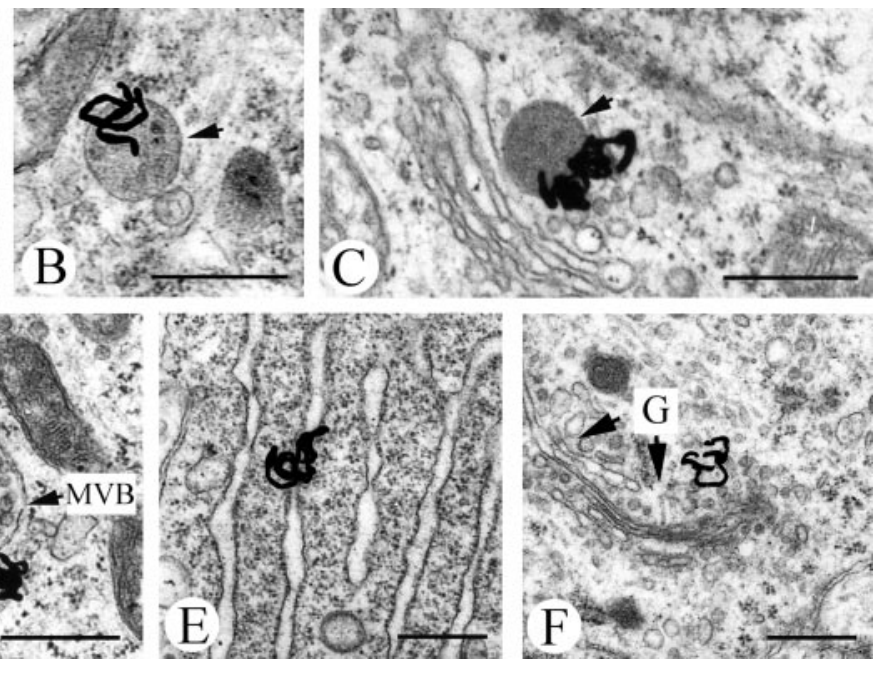

E. Ha

Figure 3. $A-F$, Representative examples of silver grain accumulation over organelles within hypoglossal motoneurons indiendosome ( $B$, arrow), CT-1 in a lysosome ( $C$, arrow), and GDNF in a heavily labeled MVB $(D)$ in the endoplasmic reticulum $(E)$ and G)-associated vesicles ( $F$, arrows). Scale bars, $500 \mathrm{~nm}$

glossal nucleus is associated with larger proteins and thus not degraded into small peptides or free ${ }^{125} \mathrm{I}_{-\mathrm{Na}^{+}}$, whereas at least half of the transported BDNF is degraded, and more than twothirds of CT-1 appears to be rapidly degraded. Interestingly, these differences in degradation between proteins show the same trends for the respective labeling densities in lysosomes (Fig. 6C, Table 1), indicating that localization in lysosomes indeed represents a valid marker for rapid degradation of the protein. Delayed degradation may involve differential kinetics of interactions between receptors for trophic factors and microtubule motor components, but precise mechanisms are currently not known.

\section{GDNF and BDNF localize to the external membrane in} dendritic MVBs but to the lumenal core in perikaryal MVBs A large fraction of internalized trophic factors accumulates in MVBs (Claude et al., 1982a). MVBs sort receptor proteins and their ligands for either degradation or recycling (Gruenberg, 2001; Sorkin and von Zastrow, 2002; Gruenberg and Stenmark, 2004). Ligands can be released from MVBs by two principal mechanisms (Fig. 7A), via traditional vesicular intermediates or exosome release (for review, see Denzer et al., 2000; Murk et al., 2002; Fevrier and Raposo, 2004). During exosome release, trophic factors would be expected among the internal vesicles, whereas they would distribute to the external membrane if membrane budding and vesicular intermediates were involved. We used EM autoradiography to localize the radioactive GDNF and BDNF by quantifying their distance from the external membrane of MVBs. Our data set for the $15 \mathrm{~h}$ time point contained a total of 119 silver grains associated with MVBs, with 78 for GDNF, and 41 silver grains for BDNF, thus allowing us to determine the suborganelle distribution of these two factors within MVBs. Because analysis of BDNF grains and GDNF grains revealed the same pattern, the data were graphed together (Fig. $7 B$ ). Our quantitative analysis shows that in dendritic MVBs (often in postsynaptic locations), the source of the radioactivity in the large majority $(80 \%)$ of grains was located within $60 \mathrm{~nm}$ distance from the external (limiting) membrane, whereas in perikaryal MVBs, the source of such silver grains was localized predominantly (>50\%) within the MVB, with a peak of distribution at 120-180 nm distance inside the external membrane (Fig. $7 B$ ). These differences 
Table 1. Fractional areas (FA), percentages of silver grains (\%), and LDs in hypoglossal motoneuron cell bodies 8 and $15 \mathrm{~h}$ after tongue injections in neonatal rat pups

\begin{tabular}{|c|c|c|c|c|c|c|c|c|c|c|c|c|c|c|c|}
\hline \multirow{3}{*}{$\begin{array}{l}\text { Protein } \\
\text { Organelle }\end{array}$} & \multirow[b]{3}{*}{ FA } & \multicolumn{4}{|c|}{ Tetanus toxin } & \multicolumn{4}{|c|}{ GDNF } & \multirow{2}{*}{\multicolumn{2}{|c|}{$\frac{\text { BDNF }}{15 \mathrm{~h}(n=234)}$}} & \multicolumn{4}{|l|}{ CT-1 } \\
\hline & & \multicolumn{2}{|c|}{$8 \mathrm{~h}(n=71)$} & \multicolumn{2}{|c|}{$15 \mathrm{~h}(n=177)$} & \multicolumn{2}{|c|}{$8 \mathrm{~h}(n=106)$} & \multicolumn{2}{|c|}{$15 \mathrm{~h}(n=210)$} & & & \multicolumn{2}{|c|}{$8 \mathrm{~h}(n=159)$} & \multicolumn{2}{|c|}{$15 \mathrm{~h}(n=152)$} \\
\hline & & $\%$ & LD & $\%$ & LD & $\%$ & LD & $\%$ & LD & $\%$ & LD & $\%$ & LD & $\%$ & LD \\
\hline Lysosome & $0.55-0.65$ & 0.0 & 0.0 & 0.8 & 1.14 & 0.5 & 0.83 & 0.0 & 0.0 & 1.6 & 3.0 & 6.1 & 10.2 & 6.6 & 10.2 \\
\hline Clear vesicle & $6.58-8.0$ & 6.8 & 0.93 & 9.6 & 1.20 & 18.0 & 2.47 & 6.8 & 0.85 & 6.6 & 1.0 & 8.0 & 1.1 & 1.6 & 0.20 \\
\hline Cytosol & $20.9-21.9$ & 22.1 & 1.03 & 20.7 & 0.99 & 12.3 & 0.41 & 31.8 & 1.52 & 18.8 & 0.86 & 16.4 & 0.77 & 16.1 & 0.77 \\
\hline Tubule & $3.39-3.4$ & 2.4 & 0.71 & 3.3 & 0.97 & 1.4 & 0.41 & 1.3 & 0.4 & 2.8 & 0.83 & 3.2 & 0.94 & 2.0 & 0.59 \\
\hline Dense endosome & $0.55-0.9$ & 7.7 & 11.0 & 5.4 & 5.70 & 6.6 & 9.43 & 2.2 & 2.42 & 5.7 & 10.4 & 14.9 & 21.3 & 18.7 & 20.8 \\
\hline Endoplasmic reticulum & $10.26-10.9$ & 19.7 & 1.87 & 16.1 & 1.46 & 20.8 & 1.96 & 6.9 & 0.63 & 13.6 & 1.33 & 11.6 & 1.09 & 10.2 & 0.94 \\
\hline MVB & 1.5-1.7 & 2.1 & 1.31 & 3.2 & 1.60 & 10.9 & 6.81 & 7.1 & 4.17 & 7.4 & 6.1 & 12.7 & 7.94 & 14.9 & 8.76 \\
\hline Mitochondrion & $9.31-9.4$ & 11.3 & 1.21 & 8.6 & 0.92 & 9.5 & 1.02 & 15.5 & 1.65 & 9.0 & 0.97 & 8.4 & 0.90 & 5.3 & 0.56 \\
\hline Plasma membrane & $1.91-2.1$ & 7.1 & 3.55 & 5.6 & 2.80 & 1.9 & 0.95 & 7.6 & 3.62 & 6.6 & 3.5 & 5.2 & 2.60 & 1.3 & 0.62 \\
\hline Light endosome & $0.59-1.0$ & 1.4 & 1.75 & 3.1 & 3.10 & 1.9 & 2.38 & 1.4 & 1.46 & 0.0 & 0.0 & 0.0 & 0.00 & 7.6 & 7.76 \\
\hline Golgi & $2.0-2.23$ & 8.9 & 4.14 & 3.7 & 1.85 & 5.4 & 2.51 & 5.8 & 2.89 & 4.6 & 2.1 & 7.0 & 3.26 & 4.3 & 2.15 \\
\hline Nucleus & $34.8-38.6$ & 5.7 & 0.16 & 12.8 & 0.37 & 9.5 & 0.26 & 8.8 & 0.25 & 16.4 & 0.42 & 3.2 & 0.09 & 8.2 & 0.24 \\
\hline Unidentified & $6.33-7.8$ & 5.1 & 0.72 & 7.1 & 0.89 & 1.4 & 0.20 & 5.7 & 0.73 & 7.2 & 1.1 & 3.4 & 0.48 & 3.3 & 0.42 \\
\hline
\end{tabular}

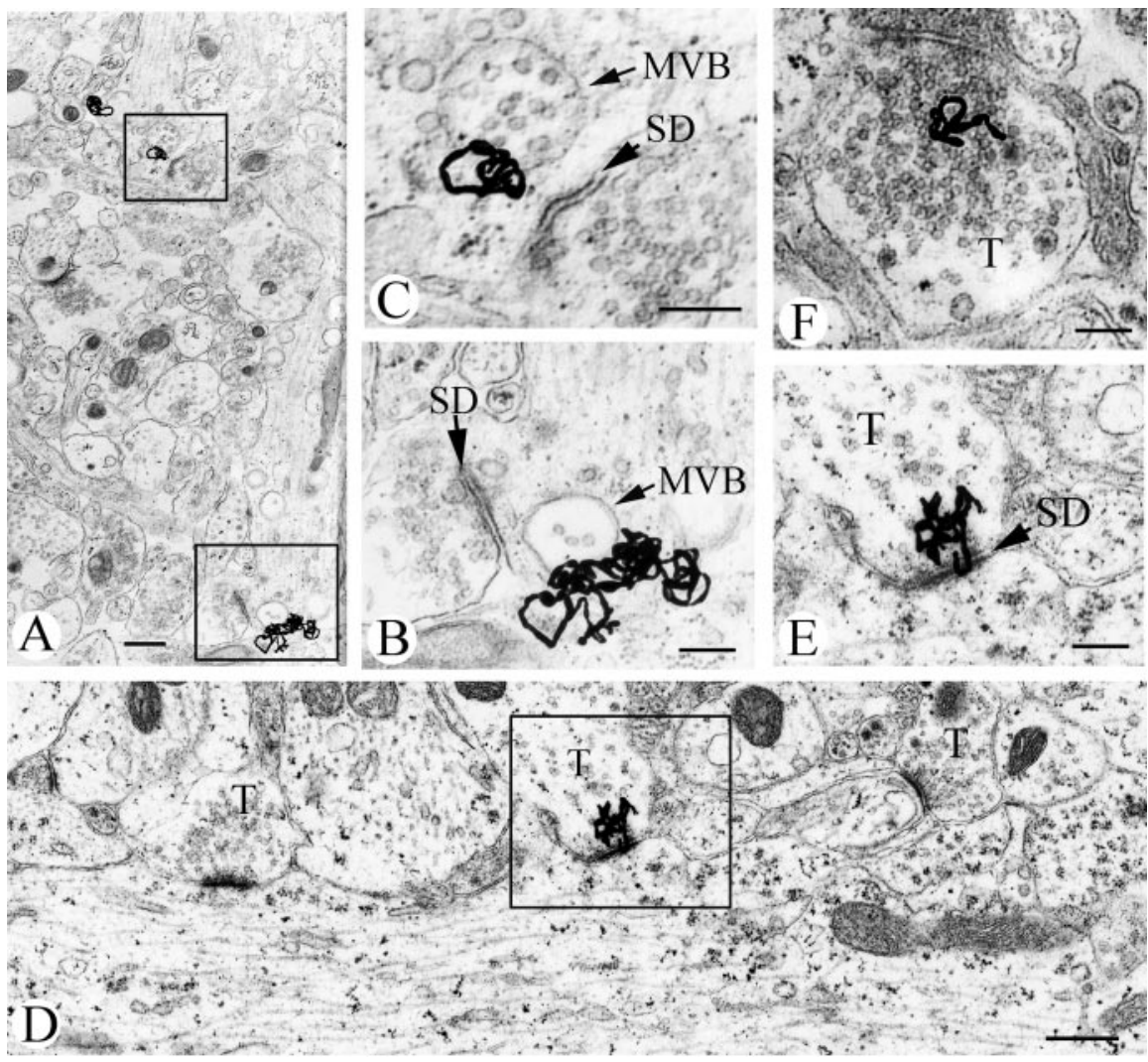

Figure 4. $A-F$, Representative examples of silver grain accumulation over MVBs and synapses within hypoglossal motoneuron dendrites indicative of localization of radiolabeled GDNF and BDNF. $A$, Boxed areas show radiolabeled GDNF associated with postsynaptic MVBs adjacent to afferent synapses. The boxed areas are shown at higher magnification in $B$ and $C$. Note that in both cases, silver grains accumulate more over the external (limiting) membrane than the core of MVBs. The synaptic densities (SD) are indicated. D, Large proximal dendrite with three synaptic terminals (T). The center synapse (boxed) is labeled with GDNF silver grains in the presynaptic region, as shown at higher magnification in E. F, Silver grain indicating BDNF is located within a terminal (T). Scale bars: $A, D, 500 \mathrm{~nm} ; B, C, E, F, 200 \mathrm{~nm}$.

between dendritic and perikaryal MVBs were statistically significant for the combined GDNF and BDNF data (Wilcoxon signed rank-sum test, $p<0.01$ and $p<0.05$ ) (Fig. $7 B$ ). The predominant localization of GDNF and BDNF at the external membrane is consistent with the classical vesicular intermediate release mechanism (Murk et al., 2002) but inconsistent with an exosome-like release from MVBs (Denzer et al., 2000) (Fig. 7A).
These data support the notion that MVBs in dendrites may be involved in synaptic recycling functions of GDNF and BDNF, whereas those in the soma may, at least in part, be a component of the classical degradation pathway. Thus, our data clarify the release mechanism of MVBs in neurons, which have been yet elusive. Importantly, our data are incompatible with the possibility that MVBs in dendrites release internal vesicles loaded with these trophic factors into the synaptic cleft as proposed in other systems for "exosomes" (Denzer et al., 2000) but rather support the traditional "intermediate vesicle" release mechanism (Murk et al., 2002) (Fig. 7A).

\section{Discussion}

We report the following: (1) trophic factors, after internalization and retrograde axonal transport, can be targeted to synapses for transsynaptic transcytosis; (2) this phenomenon is similar, but not identical to, the known transcytosis of tetanus toxin; (3) as much as $20-35 \%$ of internalized GDNF and BDNF in proximal dendrites is targeted to afferent synapses; (4) this recycling and synapse-targeting pathway is entirely absent for another target-derived and survival-promoting trophic factor, CT-1; (5) GDNF and BDNF, but not CT-1 or tetanus toxin, appear to direct multivesicular bodies to postsynaptic sites in proximal dendrites; and (6) in the case of GDNF and BDNF, the external membrane of multivesicular bodies is a prominent postsynaptic accumulation site for synapse-targeted retrograde trophic factors; this localization does not support an "exosome"-like release mechanism but argues in favor of a vesicular intermediate during the release from multivesicular bodies.

\section{The hypoglossal model system}

Before these claims can be accepted, several important features of the model system used should be emphasized. Foremost, it is 
Table 2. Fractional areas (FA), percentages of silver grains (\%), and LDs in hypoglossal motoneuron proximal dendrites and their afferent synapses 8 and $15 \mathrm{~h}$ after tongue injections in neonatal rat pups

\begin{tabular}{|c|c|c|c|c|c|c|c|c|c|c|c|c|c|c|c|}
\hline \multirow{2}{*}{\multicolumn{2}{|c|}{ Protein }} & \multicolumn{4}{|c|}{ Tetanus toxin } & \multicolumn{4}{|c|}{ GDNF } & \multirow{2}{*}{\multicolumn{2}{|c|}{$\frac{\text { BDNF }}{15 \mathrm{~h}(n=110)}$}} & \multicolumn{4}{|l|}{ CT-1 } \\
\hline & & \multicolumn{2}{|c|}{$8 \mathrm{~h}(n=62)$} & \multicolumn{2}{|c|}{$15 \mathrm{~h}(n=157)$} & \multicolumn{2}{|c|}{$8 \mathrm{~h}(n=60)$} & \multicolumn{2}{|c|}{$15 \mathrm{~h}(n=279)$} & & & \multicolumn{2}{|c|}{$8 \mathrm{~h}(n=65)$} & \multicolumn{2}{|c|}{$15 \mathrm{~h}(n=161)$} \\
\hline Organelle & $\mathrm{FA}$ & $\%$ & LD & $\%$ & LD & $\%$ & LD & $\%$ & LD & $\%$ & LD & $\%$ & LD & $\%$ & LD \\
\hline Lysosome & $0.0-0.5$ & 0.0 & 0.0 & 0.0 & 0.0 & 0.0 & 0.0 & 0.0 & 0.0 & 0.0 & 0.0 & 3.4 & 6.8 & 0.0 & 0.0 \\
\hline Clear vesicle & $3.5-4.8$ & 2.4 & 0.58 & 3.0 & 0.65 & 5.9 & 1.42 & 9.3 & 2.03 & 2.3 & 0.50 & 7.9 & 1.9 & 4.2 & 1.20 \\
\hline Cytosol & $38.6-45.1$ & 19.4 & 0.46 & 24.9 & 0.56 & 25.7 & 0.61 & 21.3 & 0.47 & 23.5 & 0.52 & 24.1 & 0.58 & 39.9 & 1.03 \\
\hline Tubule & $2.3-3.4$ & 0.5 & 0.17 & 2.8 & 0.83 & 7.9 & 2.77 & 2.0 & 0.59 & 6.8 & 2.0 & 3.5 & 1.23 & 4.0 & 1.18 \\
\hline Dense endosome & $0.67-1.4$ & 1.6 & 1.54 & 1.6 & 2.39 & 2.5 & 2.40 & 3.5 & 5.22 & 3.6 & 5.4 & 13.0 & 12.5 & 3.6 & 5.37 \\
\hline Endoplasmic reticulum & $5.1-5.2$ & 1.6 & 0.31 & 2.4 & 0.47 & 0.0 & 0.0 & 0.9 & 0.18 & 1.5 & 0.3 & 4.0 & 0.78 & 3.0 & 0.58 \\
\hline MVB & $0.5-1.4$ & 3.9 & 4.10 & 1.0 & 2.00 & 12.2 & 12.8 & 13.5 & 27.0 & 5.7 & 11.4 & 7.3 & 7.68 & 1.8 & 3.60 \\
\hline Mitochondrion & 7.1-9.7 & 3.2 & 0.38 & 4.6 & 0.65 & 2.5 & 0.30 & 5.0 & 0.70 & 4.4 & 0.6 & 9.9 & 1.18 & 11.2 & 1.57 \\
\hline Plasma membrane & $16.2-19.0$ & 16.1 & 0.91 & 14.6 & 0.90 & 24.3 & 1.38 & 19.4 & 1.20 & 13.7 & 0.85 & 17.4 & 0.99 & 16.9 & 1.04 \\
\hline Light endosome & $0.08-0.1$ & 0.0 & 0.0 & 0.0 & 0.0 & 0.0 & 0.0 & 0.1 & 1.37 & 0.0 & 0.0 & 0.0 & 0.0 & 0.03 & 0.38 \\
\hline Postsynaptic membrane & $1.7-2.2$ & 3.2 & 1.64 & 5.0 & 2.31 & 6.7 & 3.44 & 4.7 & 2.18 & 7.7 & 3.6 & 1.5 & 0.77 & 0.6 & 0.35 \\
\hline Presynaptic membrane & $3.4-3.8$ & 15.0 & 4.17 & 10.5 & 2.80 & 1.7 & 0.47 & 2.5 & 1.13 & 7.5 & 2.0 & 0.5 & 0.14 & 2.5 & 0.86 \\
\hline Terminal & $7.3-10.4$ & 29.0 & 3.26 & 27.7 & 2.78 & 5.5 & 0.62 & 13.1 & 1.90 & 19.6 & 2.7 & 3.5 & 0.39 & 6.8 & 0.65 \\
\hline Unidentified & $2.3-3.4$ & 4.0 & 1.40 & 3.0 & 1.20 & 5.0 & 1.75 & 4.7 & 1.87 & 3.7 & 1.5 & 4.0 & 1.40 & 5.3 & 2.11 \\
\hline
\end{tabular}
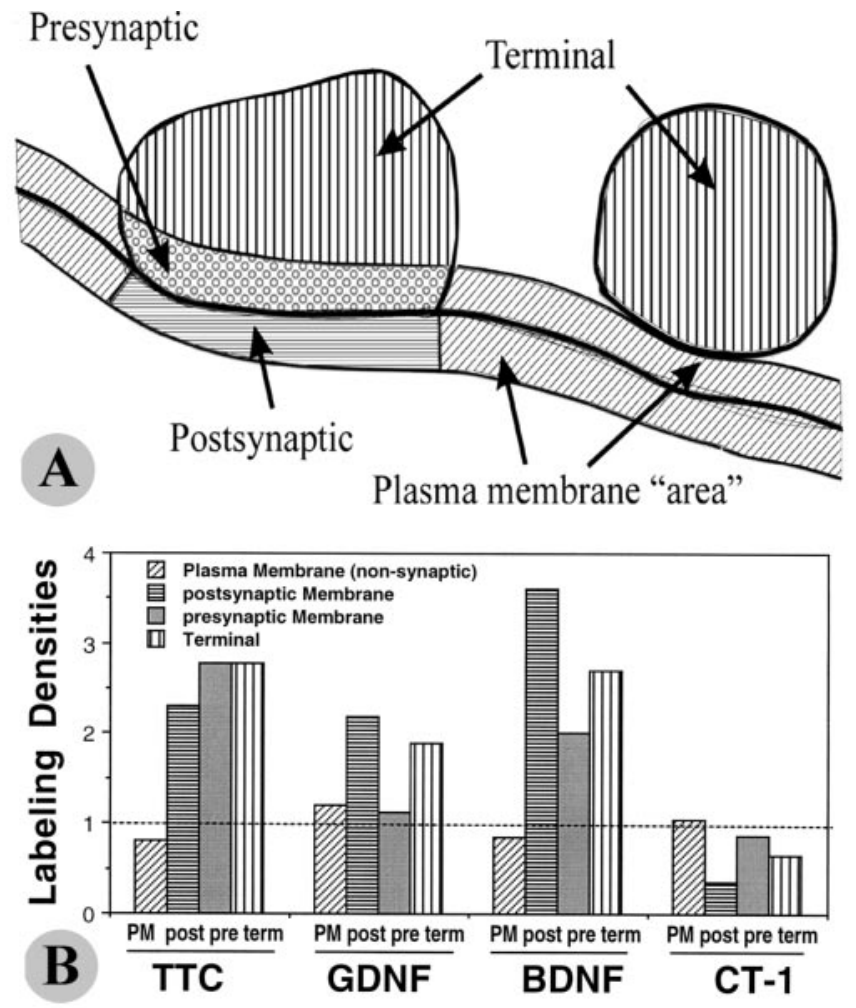

Figure 5. $A, B$, Retrogradely transported radiolabeled proteins accumulate in synapses on proximal dendrites of hypoglossal motoneurons. $A$, Diagram depicts the precise definitions used in this analysis for (nonsynaptic) plasma membrane, postsynaptic, presynaptic, and terminal areas. A distance of $150 \mathrm{~nm}$ on each side of the plasma membrane was considered within the plasma membrane area. $B$, LDs at $15 \mathrm{~h}$ of TTC and the trophic factors GDNF, BDNF, and CT- 1 are shown for the four regions as indicated in A: PM (nonsynaptic), plasma membrane; post, postsynaptic; pre, presynaptic; term, terminal. The data are based on quantitative electron microscopic autoradiography and analysis of $110-279$ silver grains for each treatment group as shown in Table 2. The dashed line indicates an $L D$ of 1.0 . An $L D$ of $\leq 1.0$ is considered nonspecific background. Note that the LD profiles for TTC, GDNF, and BDNF are similar but not identical and that (T-1 does not associate specifically with synapses (LDs of $<1.0$ ).

crucial for our claim of retrograde transcytosis that we can rule out the possibility that the radioactive material could have arrived in afferent synapses by any route other than retrograde axonal transport. This is the case, because the rat tongue lacks
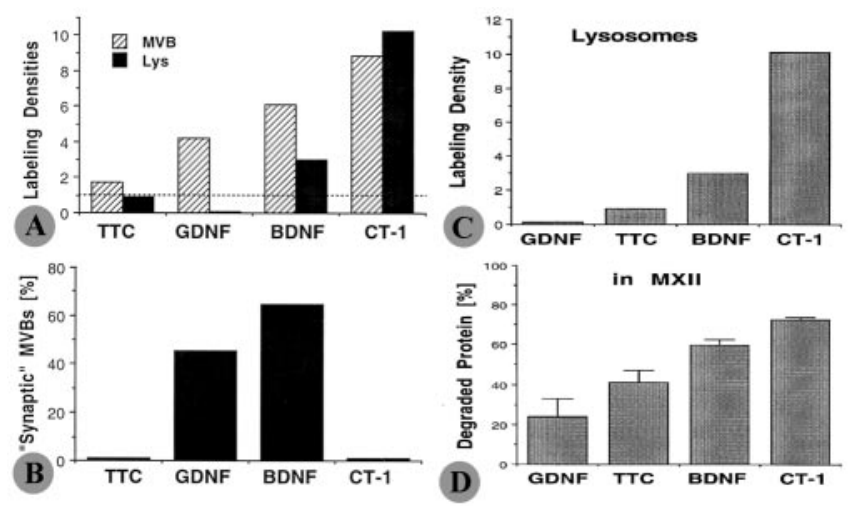

Figure 6. $A-D$, Comparison of $L D s$ and protein degradation after retrograde axonal transport to the neonatal hypoglossal nucleus. A, Comparison of LDs of TTC, GDNF, BDNF, and CT-1. Note that LDs of MVBs and lysosomes (Lys) in cell bodies are not correlated. The dotted line indicates background level. B, Quantification of MVB labeling in the vicinity (within $400 \mathrm{~nm}$ ) of postsynaptic densities in dendrites of motoneurons treated with TTC, GDNF, BDNF, or CT-1. Note that large fractions of GDNF and BDNF containing MVBs are located close to synapses. C, LDs of lysosomes differ between GDNF and TTC (background level) and BDNF (modest LD) and CT-1 (high LD).D, The LDs in ( correlate with the trends for the amount of degraded protein recovered after retrograde transport from the hypoglossal nucleus and processed for TCA precipitation. Error bars indicate SEM.

proprioceptive afferent innervation (Neuhuber and Zenker, 1989), and there is no sensory monosynaptic pathway to the hypoglossal motor nucleus in rats (Fay and Norgren, 1997; Zhang et al., 2001). Thus, the circuitry of the hypoglossal model system chosen for this analysis allows us to draw conclusions that would not be possible in spinal or trigeminal motor circuits.

\section{Degradation versus recycling pathways}

Although initial studies, particularly those on internalized NGF, emphasized the relatively rapid degradation and removal of retrogradely transported trophic factors from cell bodies (Johnson et al., 1978; Claude et al., 1982a), more recent work has revealed that a significant fraction of internalized trophic factors can avoid degradation and can be targeted to a recycling pathway, apparently for additional uses of these trophic factors (Ferguson et al., 1990; Butowt and von Bartheld, 2001; von Bartheld et al., 2001; Rind and von Bartheld, 2002a; Caleo and Cenni, 2004; von Bartheld, 2004). One such use is the targeting of internalized trophic 

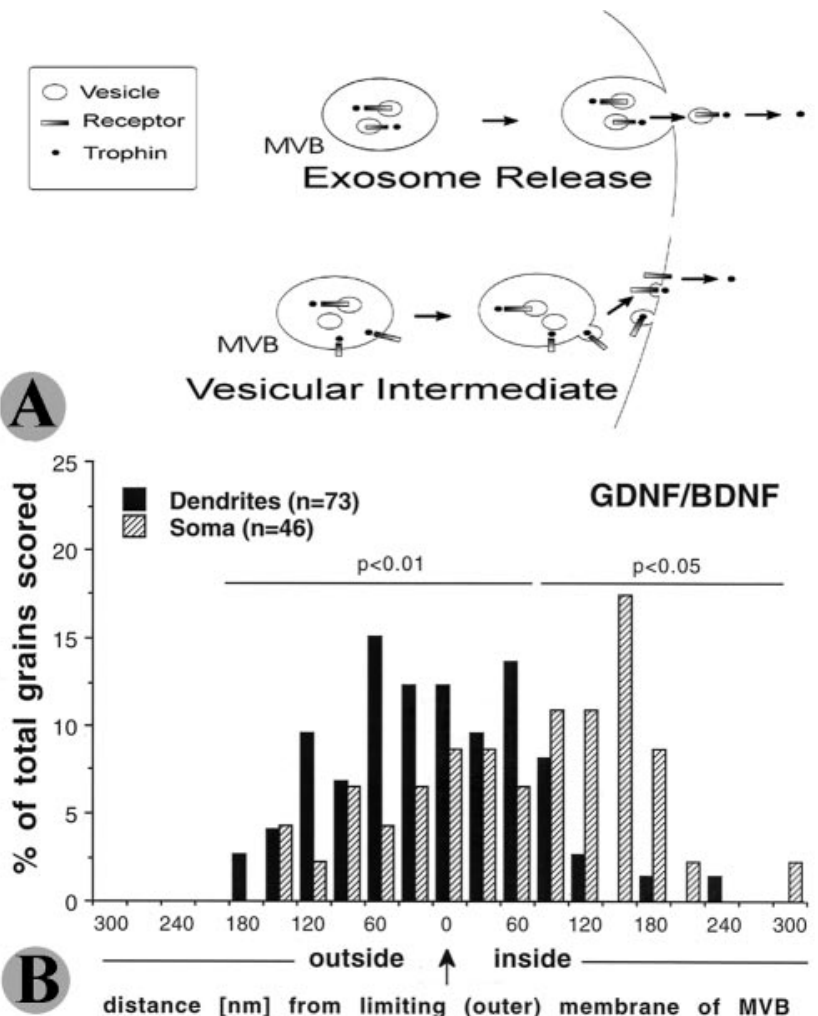

Figure 7. $A, B$, Mechanisms of release from MVBs and quantification of the distribution of BDNF and GDNF within MVBs. $A$, Schematic drawing of two alternative mechanisms of ligand release from MVBs. Recent data have described fusion of the external membrane with the plasma membrane and release of internal MVB vesicles as exosomes (top panel). The classical mechanism postulates a vesicular intermediate (similar to the initial formation of internal vesicles by external membrane budding) and subsequent transfer of such vesicles to the plasma membrane and release (bottom panel). B, Quantification of the distribution of centers of silver grains representing GDNF and BDNF relative to the external (limiting) membrane of MVBs for dendritic and somal MVBs. Note that the majority of silver grains in dendritic MVBs distribute within $60 \mathrm{~nm}$ of the outer (limiting) membrane, whereas the peak of distribution for somal MVBs is at $120-180 \mathrm{~nm}$ inside the MVB. Differences between dendritic and somal MVBs are statistically significant ( $p<0.01$ and $p<0.05$, Wilcoxon signed rank-sum test).

factors to synapses. This transcytosis pathway is used by certain macromolecules such as tetanus toxin (Schwab and Thoenen, 1976, 1977a). It has been suggested that the transsynaptic transcytosis pathway used by tetanus toxin (and apparently prions; Bartz et al., 2003) was most likely "designed" for the trafficking of trophic factors through a chain of connected neurons (interneuronal transport; Schwab and Thoenen, 1977a,b). Our study now validates these previous suggestions with the first experimental evidence and identifies two trophic factors, GDNF and BDNF, for which transsynaptic and transcytotic properties are similar (although not identical) to those of tetanus toxin.

\section{Comparison with previous studies}

Our study significantly extends previous work on the fate of retrogradely transported trophic factors. We provide the first analysis of the fate of trophic factors at the ultrastructural level in somatic cranial or spinal motoneurons. Furthermore, ours is the first comprehensive analysis of transsynaptic transcytosis of retrogradely transported trophic factors at afferent synapses. In previous studies, the fate of only NGF has been examined after retrograde axonal transport for sympathetic motoneurons in vivo (Schwab and Thoenen, 1977a) and in vitro (Claude et al., 1982a,b). These studies showed that NGF accumulated in MVBs and dense endosomes or lysosomes at the level of the cell body, and although NGF was transported into dendrites, it did not accumulate at afferent terminals, unlike tetanus toxin. The in vitro analyses (Claude et al., 1982a,b) are complicated by the fact that the fractional area of lysosomes in the neuron soma was 10 times greater than in ours or in Schwab and Thoenen's in vivo analysis (1977a), possibly because of the abnormal in vitro condition. Nevertheless, CT-1 appears to behave very similar to NGF in terms of accumulating in organelles of the degradation pathway. Both proteins are known survival factors in the systems where their transport was studied. NGF is a survival factor for sympathetic neurons (Johnson et al., 1978); CT-1 is a survival factor for hypoglossal motoneurons (Oppenheim et al., 2001). The rapid and significant accumulation of tetanus toxin in presynaptic afferent terminals in our study (LD, 2.8-4.2) (Table 2) is similar to previous reports (Schwab and Thoenen, 1976, 1977a; Price et al., 1977) (LD, 4.3-6.1). Together, these data suggest that trophic factors fall into two categories: one type that is rapidly degraded in the cell body and another type that can be recycled for transcytosis and accumulates at dendritic synapses (supplemental Fig. 1, available at www.jneurosci.org as supplemental material).

\section{Are retrograde trophic factors at synapses intact?}

For our concept that internalized and retrogradely transported trophic factors are targeted to and used by afferent synapses, it is obviously essential that such proteins are intact and that the radioactivity associated with particular synaptic organelles is not attributable to small degradation products or free iodine. We consider it highly unlikely that the analyzed radioactivity that accumulates in synapses should represent such degradation products. First, neurons rapidly expel free iodine or small degradation products (Johnson et al., 1978; Claude et al., 1982a). Because our tissue was dehydrated, free iodine would have been extracted during tissue processing and would not have remained in the tissue sample, as demonstrated by examination of the fate of free iodine (Butowt and von Bartheld, 2001). Second, the fact that two of the trophic factors (GDNF and BDNF) are degraded less than the third (CT-1) (Fig. 6C,D), but that GDNF and BDNF accumulate in synapses, unlike CT-1, is inconsistent with the possibility of degradation products accumulating in synapses. Finally, the large majority of radiolabeled GDNF and tetanus toxin (and a significant fraction of BDNF) that was recovered from hypoglossal nuclei was TCA precipitated and thus presumably was intact protein (Fig. 6D). Therefore, the overwhelming evidence indicates that the transcytosed trophic factors are intact and likely functional, although we cannot formally prove that any particular silver grain represents an intact radiolabeled protein.

\section{Are trophic factors destined for synapses trafficked and/or stored in multivesicular bodies?}

Multivesicular bodies (MVBs) accumulate internalized trophic factors with one of the highest labeling densities (Claude et al., 1982a,b; von Bartheld et al., 1996; Butowt and von Bartheld, 2001). Initially, MVBs were considered way stations for the degradation pathway, but more recent studies have suggested that these compartments are sorting organelles, where trophic factors and receptors can diverge into either degradation or recycling pathways (Felder et al., 1990; Waterman et al., 1998; Gruenberg, 2001; Gruenberg and Stenmark, 2004). Our report adds another level of complexity to the remarkable range of functions of MVBs: a strong association of GDNF- or BDNF-loaded MVBs with synaptic densities in proximal dendrites of developing motoneu- 
rons. An association of MVBs with synaptic densities, to our knowledge, has not been reported previously. These data suggest that the trophic content (cargo: receptors and/or ligands) within MVBs may entail trafficking signals (Waterman et al., 1998) and thus may direct MVBs to particular sites such as synapses (cf. Tongiorgi et al., 1997). The trafficked ligand may remain associated with its receptor as shown in Figure $7 A$, but there is no formal proof. MVB-like structures may exocytose directly by fusion of the external MVB membrane with the plasma membrane and release of internal vesicles as exosomes (Denzer et al., 2000). This mechanism has not yet been described for neurons, but prions localize in MVBs and transfer intercellularly via exosomes (Fevrier et al., 2004). Importantly, the ultrastructural distribution of GDNF and BDNF along the external membrane of MVBs is inconsistent with an exosome-like release mechanism and rather supports release via a vesicular intermediate at the synaptic cleft.

\section{Distinct fates of trophic factors responsible for survival only versus survival and synaptic plasticity}

Trophic factors such as BDNF and GDNF are known as "synaptotrophins" with significant effects on synaptic plasticity (Snider and Lichtman, 1996; Ribchester et al., 1998; Poo, 2001; Wang et al., 2002, 2003). For example, BDNF can strengthen synapses (Snider and Lichtman, 1996; Poo, 2001), and GDNF increases the release of acetylcholine (Liou et al., 1997; Ribchester et al., 1998) and dopamine (Hebert et al., 1996; Pothos et al., 1998; Bourque and Trudeau, 2000). In contrast, CT-1, which promotes the survival of rodent hypoglossal motoneurons (Oppenheim et al., 2001), appears to be rapidly degraded after delivery at the cell body, similar to the survival-promoting NGF in other systems (Johnson et al., 1978). Interestingly, NGF is a survival factor (like CT-1) with little, if any, effects on synaptic plasticity in the motor system (Lohof et al., 1993; Yan et al., 1993; Poo, 2001). Thus, trophic factors with "sole" survival functions appear to be rapidly degraded after internalization, whereas those with additional synaptic functions can follow to a significant extent a recycling pathway (supplemental Fig. 1, available at www.jneurosci.org as supplemental material). These findings may have clinical implications when trophic factors are used as therapeutic devices and targeted for delivery to particular populations of neurons (Bordet et al., 2001; Caleo and Cenni, 2004; von Bartheld, 2004).

\section{References}

Arce V, Pollock RA, Philippe JM, Pennica D, Henderson CE, deLapeyriere O (1998) Synergistic effects of Schwann- and muscle-derived factors on motoneuron survival involve GDNF and cardiotrophin-1 (CT-1). J Neurosci 18:1440-1448.

Bartz JC, Kincaid AE, Bessen RA (2003) Rapid prion neuroinvasion following tongue infection. J Virol 77:583-591.

Blesch A, Tuszynski MH (2001) GDNF gene delivery to injured adult CNS motor neurons promotes axonal growth, expression of the trophic neuropeptide CGRP, and cellular protection. J Comp Neurol 436:399-410.

Bordet T, Castelnau-Ptakhine L, Fauchereau F, Friocourt G, Kahn A, Haase G (2001) Neuronal targeting of cardiotrophin-1 by coupling with tetanus toxin C fragment. Mol Cell Neurosci 17:842-854.

Bourque MJ, Trudeau LE (2000) GDNF enhances the synaptic efficacy of dopaminergic neurons in culture. Eur J Neurosci 12:3172-3180.

Butowt R, von Bartheld CS (2001) Sorting of internalized neurotrophins into an endocytic transcytosis pathway via the Golgi system: ultrastructural analysis in retinal ganglion cells. J Neurosci 21:8915-8930.

Butowt R, von Bartheld CS (2003) Connecting the dots: trafficking of neurotrophins, lectins and diverse pathogens by binding to the neurotrophin receptor p75NTR. Eur J Neurosci 17:673-680.

Caleo M, Cenni MC (2004) Anterograde transport of neurotrophic factors: possible therapeutic implications. Mol Neurobiol 29:179-196.
Caro LG, van Tubergen RP (1962) High resolution autoradiography. I. Methods. J Cell Biol 15:173-188.

Chen J, Butowt R, Rind HB, von Bartheld CS (2003) GDNF increases the survival of developing oculomotor neurons through a target-derived mechanism. Mol Cell Neurosci 24:41-56.

Chiu AY, Chen EW, Loera S (1994) Distinct neurotrophic responses of axotomized motor neurons to BDNF and CNTF in adult rats. NeuroReport 5:693-696.

Claude P, Hawrot E, Dunis DA, Campenot RB (1982a) Binding, internalization, and retrograde transport of ${ }^{125} \mathrm{I}$-nerve growth factor in cultured rat sympathetic neurons. J Neurosci 2:431-442.

Claude P, Hawrot E, Parada I (1982b) Ultrastructural studies on the intracellular fate of 125I-nerve growth factor in cultured rat sympathetic neurons. J Cell Biochem 20:1-13.

Denzer K, Kleijmeer MJ, Heijnen HF, Stoorvogel W, Geuze HJ (2000) Exosome: from internal vesicle of the multivesicular body to intercellular signaling device. J Cell Sci 113:3365-3374.

DiStefano PS, Friedman B, Radziejewski C, Alexander C, Boland P, Schick CM, Lindsay RM, Wiegand SJ (1992) The neurotrophins BDNF, NT-3, and NGF display distinct patterns of retrograde axonal transport in peripheral and central neurons. Neuron 8:983-993.

Dumas M, Schwab ME, Thoenen H (1979) Retrograde axonal transport of specific macromolecules as a tool for characterizing nerve terminal membranes. J Neurobiol 10:179-197.

Fay RA, Norgren R (1997) Identification of rat brainstem multisynaptic connections to the oral motor nuclei using pseudorabies virus. III. Lingual muscle motor systems. Brain Res Rev 25:291-311.

Felder S, Miller K, Moehren G, Ullrich A, Schlessinger J, Hopkins CR (1990) Kinase activity controls the sorting of the epidermal growth factor receptor within the multivesicular body. Cell 61:623-634.

Ferguson IA, Schweitzer JB, Johnson Jr EM (1990) Basic fibroblast growth factor: receptor-mediated internalization, metabolism, and anterograde axonal transport in retinal ganglion cells. J Neurosci 10:2176-2189.

Fertuck HC, Salpeter MM (1974) Sensitivity in electron microscope autoradiography for 125I. J Histochem Cytochem 22:80-87.

Fevrier B, Raposo G (2004) Exosomes: endosomal-derived vesicles shipping extracellular messages. Curr Opin Cell Biol 16:415-421.

Fevrier B, Vilette D, Archer F, Loew D, Faigle W, Vidal M, Laude H, Raposo G (2004) Cells release prions in association with exosomes. Proc Natl Acad Sci USA 101:9683-9688.

Fishman PS, Carrigan DR (1987) Retrograde transneuronal transfer of the C-fragment of tetanus toxin. Brain Res 406:275-279.

Grothe C, Unsicker K (1992) Basic fibroblast growth factor in the hypoglossal system: specific retrograde transport, trophic, and lesion-related responses. J Neurosci Res 32:317-328.

Gruenberg J (2001) The endocytic pathway: a mosaic of domains. Nat Rev Mol Cell Biol 2:721-730.

Gruenberg J, Stenmark H (2004) The biogenesis of multivesicular endosomes. Nat Rev Mol Cell Biol 5:317-323.

Haubensak W, Narz F, Heumann R, Lessmann V (1998) BDNF-GFP containing secretory granules are localized in the vicinity of synaptic junctions of cultured cortical neurons. J Cell Sci 111:1483-1493.

Hebert MA, Van Horne CG, Hoffer BJ, Gerhardt G (1996) Functional effects of GDNF in normal rat striatum: presynaptic studies using in vivo electrochemistry and microdialysis. J Pharmacol Exp Ther 279:1181-1190.

Johnson Jr EM, Andres RY, Bradshaw RA (1978) Characterization of the retrograde transport of nerve growth factor (NGF) using high specific activity [125I] NGF. Brain Res 150:319-331.

LaVail JH, Sugino IK, McDonald DM (1983) Localization of axonally transported 125I-wheat germ agglutinin beneath the plasma membrane of chick retinal ganglion cells. J Cell Biol 96:373-381.

Leitner ML, Molliver DC, Osborne PA, Vejsada R, Golden JP, Lampe PA, Kato AC, Milbrandt J, Johnson Jr EM (1999) Analysis of the retrograde transport of glial cell line-derived neurotrophic factor (GDNF), neurturin, and persephin suggests that in vivo signaling for the GDNF family is GFR $\alpha$ coreceptor-specific. J Neurosci 19:9322-9331.

Lessmann V, Gottmann K, Malcangio M (2003) Neurotrophin secretion: current facts and future prospects. Prog Neurobiol 69:341-374.

Liou JC, Yang RS, Fu WM (1997) Regulation of quantal secretion by neurotrophic factors at developing motoneurons in Xenopus cell cultures. J Physiol (Lond) 503:129-139.

Lohof AM, Ip NY, Poo MM (1993) Potentiation of developing neuromus- 
cular synapses by the neurotrophins NT-3 and BDNF. Nature 363:350-353.

Miana-Mena FJ, Munoz MJ, Ciriza J, Soria J, Brulet P, Zaragoza P, Osta R (2003) Fragment $C$ tetanus toxin: a putative activity-dependent neuroanatomical tracer. Acta Neurobiol Exp (Wars) 63:211-218.

Murk JL, Stoorvogel W, Kleijmeer MJ, Geuze HJ (2002) The plasticity of multivesicular bodies and the regulation of antigen presentation. Semin Cell Dev Biol 13:303-311.

Neuhuber WL, Zenker W (1989) Central distribution of cervical primary afferents in the rat, with emphasis on proprioceptive projections to vestibular, perihypoglossal, and upper thoracic spinal nuclei. J Comp Neurol 280:231-253.

Nunez-Abades PA, He F, Barrionuevo G, Cameron WE (1994) Morphology of developing rat genioglossal motoneurons studied in vitro: changes in length, branching pattern, and spatial distribution of dendrites. J Comp Neurol 339:401-420.

Oppenheim RW (1996) Neurotrophic survival molecules for motoneurons: an embarrassment of riches. Neuron 17:195-197.

Oppenheim RW, Houenou LJ, Parsadanian AS, Prevette D, Snider WD, Shen L (2000) Glial cell line-derived neurotrophic factor and developing mammalian motoneurons: regulation of programmed cell death among motoneuron subtypes. J Neurosci 20:5001-5011.

Oppenheim RW, Wiese S, Prevette D, Armanini M, Wang S, Houenou LJ, Holtmann B, Gotz R, Pennica D, Sendtner M (2001) Cardiotrophin-1, a muscle-derived cytokine, is required for the survival of subpopulations of developing motoneurons. J Neurosci 21:1283-1291.

Paxinos G, Watson C (1998) The rat brain in stereotaxic coordinates, Ed 4. San Diego: Academic.

Peters A, Palay SL, Webster HF (1991) The fine structure of the nervous system, Ed 3. New York: Oxford UP.

Poo MM (2001) Neurotrophins as synaptic modulators. Nat Rev Neurosci 2:24-32.

Pothos EN, Davila V, Sulzer D (1998) Presynaptic recording of quanta from midbrain dopamine neurons and modulation of the quantal size. J Neurosci 18:4106-4118.

Price DL, Griffin JW, Peck K (1977) Tetanus toxin: evidence for binding at presynaptic nerve endings. Brain Res 121:379-384.

Ribchester RR, Thomson D, Haddow LJ, Ushkaryov YA (1998) Enhancement of spontaneous transmitter release at neonatal mouse neuromuscular junctions by the glial cell line-derived neurotrophic factor (GDNF). J Physiol (Lond) 512:635-641.

Rind HB, von Bartheld CS (2002a) Anterograde axonal transport of internalized GDNF in sensory and motor neurons. NeuroReport 13:659-664.

Rind HB, von Bartheld CS (2002b) Target-derived cardiotrophin-1 and insulin-like growth factor-I promote neurite growth and survival of developing oculomotor neurons. Mol Cell Neurosci 19:58-71.

Rind HB, von Bartheld CS (2002c) Synaptic targeting of retrogradely transported GDNF. Soc Neurosci Abstr 28:428.13.

Rind HB, Butowt R, von Bartheld CS (2004) Synaptic targeting of retrogradely transported neurotrophic factors in motoneurons: comparison of GDNF, BDNF, and CT-1 with tetanus toxin. Soc Neurosci Abstr 30:726.3.

Russell FD, Koishi K, Jiang Y, McLennan IS (2000) Anterograde axonal transport of glial cell line-derived neurotrophic factor and its receptors in rat hypoglossal nerve. Neuroscience 97:575-580.

Salpeter MM, McHenry FA, Salpeter EE (1978) Resolution of electron microscope autoradiography. IV. Application to analysis of autoradiographs. J Cell Biol 76:127-145.

Schwab ME, Thoenen H (1976) Electron microscopic evidence for a transsynaptic migration of tetanus toxin in spinal cord motoneurons: an autoradiographic and morphometric study. Brain Res 105:213-227.
Schwab M, Thoenen H (1977a) Selective trans-synaptic migration of tetanus toxin after retrograde axonal transport in peripheral sympathetic nerves: a comparison with nerve growth factor. Brain Res 122:459-474.

Schwab ME, Thoenen H (1977b) Retrograde axonal and transsynaptic transport of macromolecules: physiological and pathophysiological importance. Agents Actions 7:361-368.

Schwab ME, Suda K, Thoenen H (1979) Selective retrograde transsynaptic transfer of a protein, tetanus toxin, subsequent to its retrograde axonal transport. J Cell Biol 82:798-810.

Sendtner M (1996) Neurotrophic factors for experimental treatment of motoneuron disease. Prog Brain Res 109:365-371.

Snider WD, Lichtman JW (1996) Are neurotrophins synaptotrophins? Mol Cell Neurosci 7:433-442.

Sorkin A, von Zastrow M (2002) Signal transduction and endocytosis: close encounters of many kinds. Nat Rev Mol Cell Biol 3:600-614.

Strelau J, Schober A, Sullivan A, Schilling L, Unsicker K (2003) Growth/ differentiation factor-15 (GDF-15), a novel member of the TGF-beta superfamily, promotes survival of lesioned mesencephalic dopaminergic neurons in vitro and in vivo and is induced in neurons following cortical lesioning. J Neural Transm Suppl 65:197-203.

Takasu N, Hashimoto PH (1988) Morphological identification of an interneuron in the hypoglossal nucleus of the rat: a combined Golgi-electron microscopic study. J Comp Neurol 271:461-471.

Tongiorgi E, Righi M, Cattaneo A (1997) Activity-dependent dendritic targeting of BDNF and TrkB mRNAs in hippocampal neurons. J Neurosci 17:9492-9505.

Vaughn JE (1989) Fine structure of synaptogenesis in the vertebrate central nervous system. Synapse 3:255-285.

von Bartheld CS (2001) Tracing with radiolabeled neurotrophins. Methods Mol Biol 169:195-216.

von Bartheld CS (2004) Axonal transport and neuronal transcytosis of trophic factors, tracers and pathogens. J Neurobiol 58:295-314.

von Bartheld CS, Byers MR, Williams R, Bothwell M (1996) Anterograde transport of neurotrophins and axodendritic transfer in the developing visual system. Nature 379:830-833.

von Bartheld CS, Wang X, Butowt R (2001) Anterograde axonal transport, transcytosis, and recycling of neurotrophic factors: the concept of trophic currencies in neural networks. Mol Neurobiol 24:1-28.

Wan XS, Trojanowski JQ, Gonatas JO, Liu CN (1982) Cytoarchitecture of the extranuclear and commissural dendrites of hypoglossal nucleus neurons as revealed by conjugates of horseradish peroxidase with cholera toxin. Exp Neurol 78:167-175.

Wang CY, Yang F, He XP, Je HS, Zhou JZ, Eckermann K, Kawamura D, Feng L, Shen L, Lu B (2002) Regulation of neuromuscular synapse development by glial cell line-derived neurotrophic factor and neurturin. J Biol Chem 277:10614-10625.

Wang X, Butowt R, von Bartheld CS (2003) Presynaptic neurotrophin-3 increases the number of tectal synapses, vesicle density, and number of docked vesicles in chick embryos. J Comp Neurol 458:62-77.

Wang XH, Poo MM (1997) Potentiation of developing synapses by postsynaptic release of neurotrophin-4. Neuron 19:825-835.

Waterman H, Sabanai I, Geiger B, Yarden Y (1998) Alternative intracellular routing of ErbB receptors may determine signaling potency. J Biol Chem 273:13819-13827.

Yan Q, Elliott JL, Matheson C, Sun J, Zhang L, Mu X, Rex KL, Snider WD (1993) Influences of neurotrophins on mammalian motoneurons in vivo. J Neurobiol 24:1555-1577.

Zhang J, Luo P, Pendlebury WW (2001) Light and electron microscopic observations of a direct projection from mesencephalic trigeminal nucleus neurons to hypoglossal motoneurons in the rat. Brain Res 917:67-80. 